\title{
Knockdown of Tripartite Motif Containing 28 suppresses the migration, invasion and epithelial-mesenchymal transition in ovarian carcinoma cells through down-regulation of $\mathrm{Wnt} / \beta$-catenin signaling pathway
}

\author{
B. DENG ${ }^{1, \star}$, S. ZHANG ${ }^{2}$, Y. ZHANG ${ }^{1}$, Y. MIAO ${ }^{3}, \mathrm{X} \mathrm{MENG}^{1}, \mathrm{~K}^{\mathrm{K}} \mathrm{GUO}^{1}$
}

${ }^{1}$ Department of Gynecology, The First Affiliated Hospital of China Medical University, Shenyang 110001, People's Republic of China; ${ }^{2}$ Central Laboratory, China Medical University, Shenyang, 110001, People's Republic of China; ${ }^{3}$ Department of Pathology, The First Affiliated Hospital and College of Basic Medical Sciences, China Medical University, Shenyang 110001, People's Republic of China

*Correspondence: dengboyacmu@163.com

Received September 18, 2016 / Accepted April 20, 2017

\begin{abstract}
Tripartite motif containing 28 (TRIM28) is a transcriptional corepressor of Kruppel-associated box zinc finger protein, which has been reported to participate in carcinogenesis. Nonetheless, whether TRIM28 plays a role in the metastasis of ovarian carcinoma (OC) is unclear and requires further investigation. In this study, two OC cell lines (A2780 and OVCAR-3) with stable low expression of TRIM28 were established via RNA interference. We found that the migratory and invasive ability of TRIM28-silenced OC cells significantly decreased. The expression and activity of matrix metallopeptidase (MMP)-2 and MMP-9 in these OC cells were inhibited. The TRIM28 shRNA also suppressed the epithelial-mesenchymal transition (EMT) of OC cells as evidenced by the up-regulated E-cadherin and the downregulated Vimentin and N-cadherin. Additionally, the Wnt/ $\beta$-catenin signaling pathway was suppressed in TRIM28-silenced OC cells: the activity of $\beta$-catenin was inhibited, the expression of total and nuclear $\beta$-catenin, Axin 2, T-cell factor 1 (TCF1) and lymphoid enhancer binding factor 1 (LEF1) were decreased, whereas the phosphorylation of $\beta$-catenin at Ser33/37 was enhanced. Further, re-expression of active $\beta$-catenin in TRIM28-silenced OC cells partly restored their metastasis in vitro. Taken together, our study demonstrates a contributory role of TRIM28 in OC metastasis in vitro, suggesting TRIM28 as a novel therapeutic target for this malignant tumor.
\end{abstract}

Key words: TRIM28, ovarian carcinoma, EMT, metastasis

Ovarian carcinoma (OC) has the highest fatality rate among the female reproductive system malignant tumors [1]. Women with OC often have no typical symptoms until the disease reaches an advanced stage with peritoneal dissemination and massive ascites [2]. Debulking surgery and chemotherapy are currently the most commonly used therapies for OC treatment [3], but the 5-year survival rate of OC patients is only $45 \%$ [4]. It is necessary to explore new molecular mechanisms and to identify new potential therapeutic targets to improve OC treatment.

Tripartite motif containing 28 (TRIM28) is a nuclear corepressor of Kruppel-associated box zinc finger protein and it has an $\mathrm{N}$ terminal RBCC domain that consists of a really interesting new gene finger (RING), two B-box zinc fingers and a coiled coil domain [5]. Previous reports have demonstrated that TRIM28 is participated in multiple biological processes, including senescence [6], skeletal muscle differentiation [7], pluripotent stem cell reprogramming [8], and chromatin modification [9]. In recent years, increasing evidences indicate that TRIM28 plays a critical role in tumor development and metastasis. TRIM28 facilitates the progression of proliferation and metastasis in breast cancer cells [10]. TRIM28 is overexpressed in pancreatic tumor tissue and indicates a poor clinic outcome, and its force overexpression in pancreatic cancer cells increases their invasion and migration [11]. Similar cancer promoting effects of TRIM28 have also been reported in glioma [12] and lung cancer [13]. Of note, Cui Y et al. have demonstrated that the elevated expression of TRIM28 is associated with the aggressive clinical features in OC patients [14].

The process of epithelial-mesenchymal transition (EMT) is characterized by which epithelial cells loss cell-cell adhesion and polarity and acquire motile and invasive properties to become mesenchymal-like cells. EMT is considered to be an important 
procedure during tumor cell metastasis [15]. Presence of distant metastasis is associated with a much higher risk of causing death in cancer [16]. Therefore, a deeper investigation on the molecular mechanisms of EMT will help us understand the metastatic processes of cancer cells, and provide new therapeutic targets for the treatment of cancer. Interestingly, TRIM28 is found to be involved in the activation of EMT in both normal cells, such as fibroblasts [17], and malignant cells, such as lung cancer cells [18] and cervical cancer cells [19]. Nevertheless, whether TRIM28 is participated in the EMT process of OC cells is almost unknown and needs to be elucidated.

In the present study, we explored the role of TRIM28 in the migration and invasion of OC cells by knocking down its expression. The underlying mechanisms with a focus on EMT process were also investigated.

\section{Materials and methods}

Cell lines and cell culture. Human ovarian carcinoma cell line OVCAR-3 was obtained from Shanghai Cell Biology Institute, Chinese Academy of Sciences, while A2780 cell line was purchased from Chi Scientific, Inc. These cells were cultured in RPMI 1640 (GibCo, Grand Island, NY, USA) containing with $10 \%$ fetal bovine serum (Hyclone, Logan, Utah, USA), and maintained in a humidified atmosphere with $5 \% \mathrm{CO}_{2}$ at $37^{\circ} \mathrm{C}$.

\section{A}

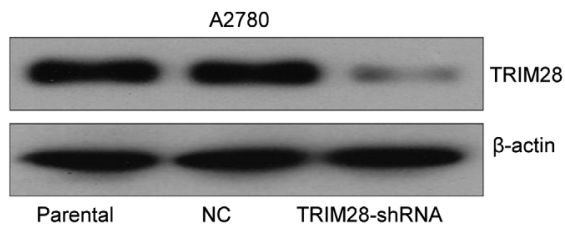

B
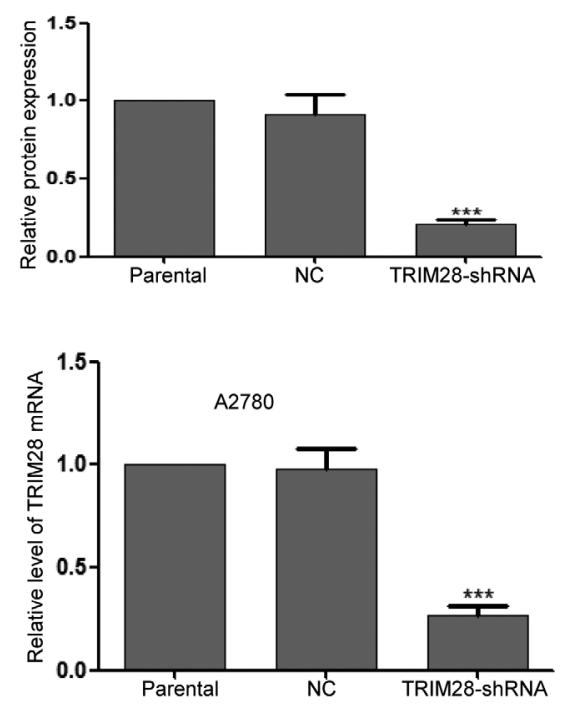

RNA interference of TRIM28. The TRIM28 targeted interference sequence and non-specific control (NC) sequence were designed and synthesized as follows: TRIM28 sh-RNA (forward): 5'-GATCCCCGGGATGGTGAACGTACTGTTTCAAGAGAACAGTACGTTCACCATCCCTTTTT-3';NCshRNA(forward): 5'- GATCCCCTTCTCCGAACGTGTCACGTTTCAAGAGAACGTGACACGTTCGGAGAATTTTT -3'. These DNA segments were cloned into pRNA-H1.1 expression vector. A2780 and OVCAR- 3 cells were transfected with certain plasmid by using Lipofectamine 2000 agent (Invitrogen, Carlsbad, CA, USA). Stably transfected cell lines were obtained by screening with G418 in a final concentration of $200 \mu \mathrm{g} / \mathrm{mL}$.

Western blotting analysis. Total protein and nucleoprotein were isolated with the RIPA lysis buffer (Beyotime, Shanghai, China) and the nuclear and cytoplasmic protein extraction kit (Beyotime) according to the manufacturer's instructions, respectively. Protein concentrations were determined with an enhanced BCA protein assay kit (Beyotime). Samples were then separated by $10 \%$ SDS-PAGE and transferred onto polyvinylidene fluoride (PVDF) membranes. Membranes were blocked $1 \mathrm{~h}$ by $5 \%$ milk and incubated in primary antibodies against TRIM28 (1:200, Santa cruz, sc-19169), matrix metallopeptidase (MMP)-2 (1:400, BOSTER, BA0569), MMP9 (1:400, BOSTER, BA0573), E-cadherin (1:400, BOSTER, BA0474), Vimentin (1:500, Bioss, bs-8533R), N-cadherin (1:400, BOSTER, BA0673), $\beta$-catenin (1:400, BOSTER, BA0426), p- $\beta$-catenin
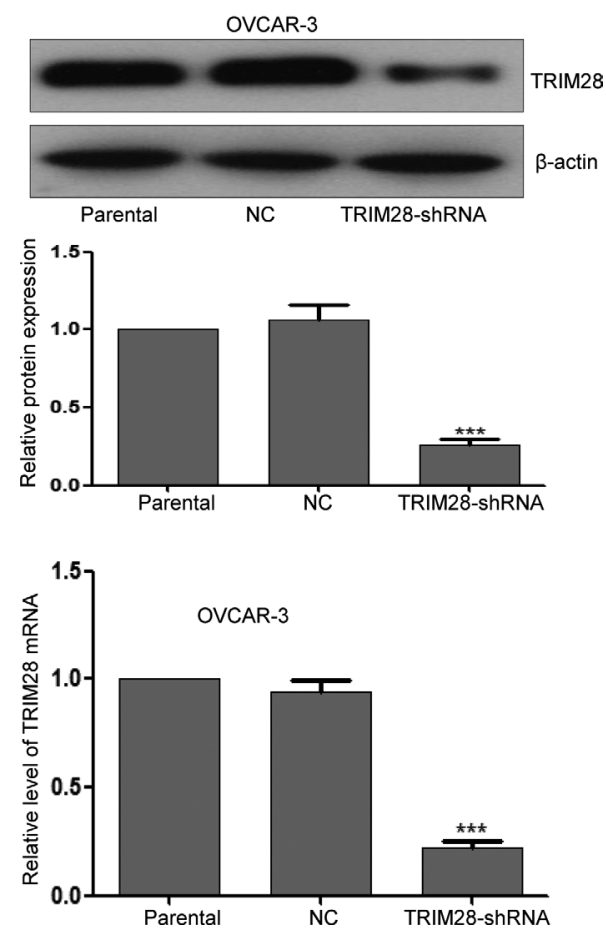

Figure 1. Knockdown of TRIM28 in A2780 and OVCAR-3 cells. (A) Western blot was performed to detect the expression of TRIM28 in TRIM28-silenced A2780 and OVCAR-3 cells. (B) The expression level of TRIM28 was measured by real-time PCR after knockdown of TRIM28 in A2780 and OVCAR-3 cells. Date were presented as mean $\pm \mathrm{SD}$. ${ }^{\star * *} \mathrm{p}<0.001$ versus the NC group. 
(1:500, BOSTER, bs-4074R) and $\beta$-actin (1:1000, Santa cruz, sc-47778) overnight at $4^{\circ} \mathrm{C}$. Thereafter, the membranes were incubated with HRP-conjugated secondary antibodies for $1 \mathrm{~h}$, and the protein blots were visualized via the enhanced chemiluminescence (Beyotime). The expression level of a target protein was normalized to $\beta$-actin or Histone 3 .

Total RNA extraction and real-time quantitative RTPCR. RNApurel Kit (BioTeke, Beijing, China) was applied to extract the total RNA from OC cells following the manufacturer's instructions. Purified RNA was used for cDNA synthesis by reverse transcription using M-MLV Reverse Transcriptase (BioTeke). Real-time quantitative PCR was performed in 96 -well plates in a $20-\mu \mathrm{L}$ reaction system containing $1 \mu \mathrm{L}$ template cDNA, $10 \mu \mathrm{L}$ SYBR GREEN mastermix (2X) and $0.5 \mu \mathrm{L}$ forward and reverse primers $(10 \mu \mathrm{M}$ of primer concentration). Gene expression was calculated by using the $2^{-\triangle \Delta C T}$ method and normalized to $\beta$-actin.

Wound healing assay. Wound healing assay was performed to measure the migration ability of OC cells. In short, OC cells seeded in 6 plates were cultured to $70-80 \%$ confluence. Then cells were transfected with certain plasmid for $24 \mathrm{~h}$ and followed by scraping a straight line to create a "scratch" at the bottom of culture dish. Cell images at the beginning, or $12 \mathrm{~h}$ and $24 \mathrm{~h}$ after scratch were captured using a phase-contrast microscope.

Transwell assay. Transwell assay was used to detect the invasive ability of OC cells. Briefly, OC cells were first grown in 6-well plates and transfected with certain plasmid for $24 \mathrm{~h}$. Then, these cells were harvested and suspended in serum-free medium $\left(1 \times 10^{5} \mathrm{cells} / \mathrm{mL}\right)$ and placed into the transwell chambers pre-coated with Matrigel (BD, Franklin Lakes, New Jersey, USA). Twenty-four hours later, cells in the upper chambers were gently discarded. Cells on the underside of membranes were fixed with $4 \%$ paraformaldehyde for $20 \mathrm{~min}$, stained with $0.5 \%$ crystal violet for $5 \mathrm{~min}$, and then counted in five randomly selected fields. Each assay was performed in triplicate.

Gelatin zymography assay. The activities of MMP-9 and MMP-2 were evaluated by gelatin zymography assay. In
A
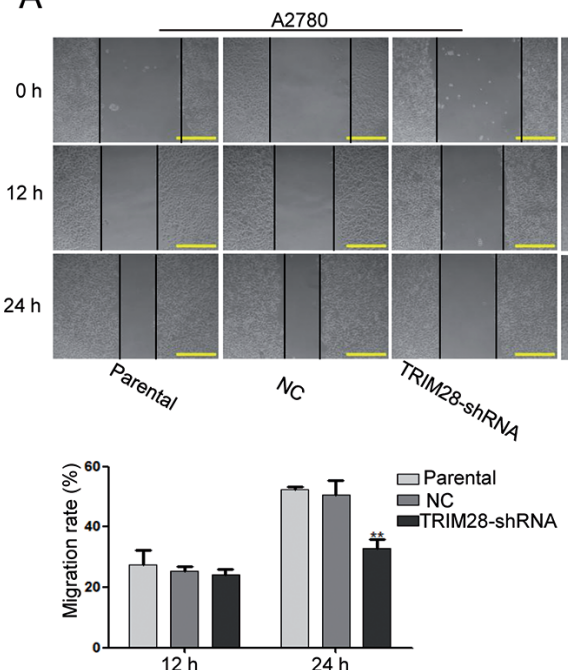

C

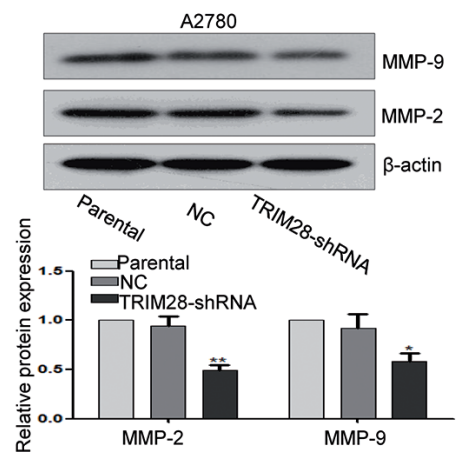

B
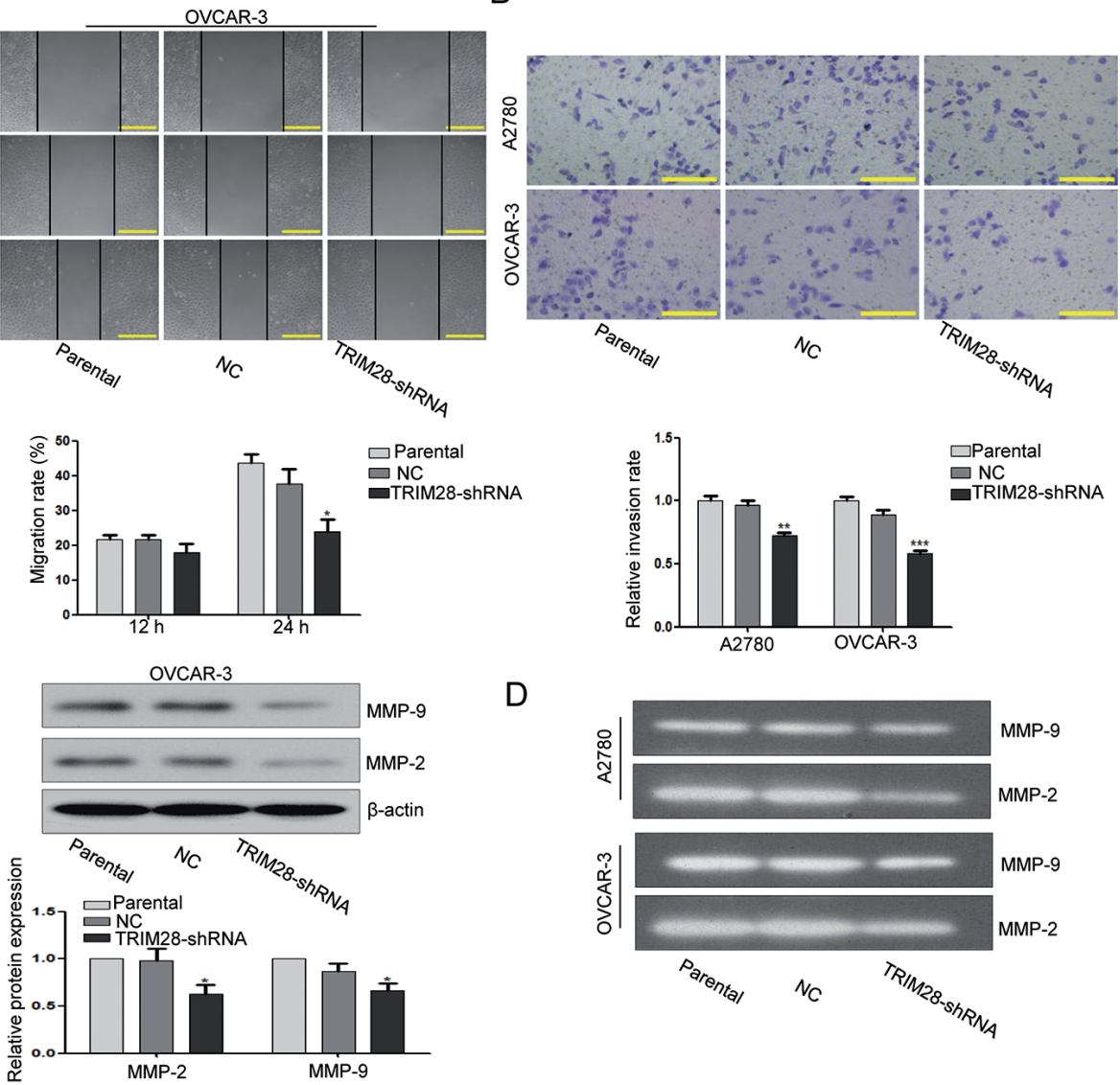

D

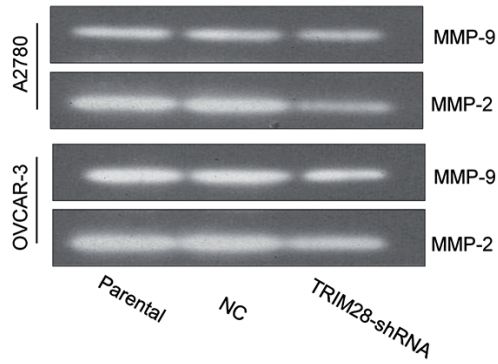

Figure 2. Knockdown of TRIM28 inhibited the ability of migration and invasion of OC cells. (A) The ability of migration was assessed by wound healing assay after silencing of TRIM28 in A2780 and OVCAR-3 cells. (B) The invasiveness was evaluated by transwell assay after TRIM28 silencing in A2780 and OVCAR-3 cells. (C) Western blot was used to detect the protein levels of MMP-2 and MMP-9 in TRIM28-silenced A2780 and OVCAR-3 cells. (D) Gelatin zymography assay was applied to measure the MMP-2 and MMP-9 activity after knockdown of TRIM28 in A2780 and OVCAR-3 cells. Date were presented as mean $\pm \mathrm{SD} .{ }^{\star} \mathrm{p}<0.05,{ }^{* *} \mathrm{p}<0.01$ and ${ }^{\star * *} \mathrm{p}<0.001$ versus the NC group. 
short, protein samples were separated by $10 \%$ SDS-PAGE gels containing $1 \mathrm{mg} / \mathrm{ml}$ gelatin (sigma, G1890). Then, gels were re-natured in 2.5\% Triton X-100 (AMRESCO, 694) solution for 40 min twice at room temperature (RT). The gels were then treated with incubation buffer at $37^{\circ} \mathrm{C}$ for $40 \mathrm{~h}$. Coomassie brilliant blue R-250 (0.05\%; AMRESCO, 0742) was used to stain gels for $3 \mathrm{~h}$ at RT. MMP-2 and MMP-9 activities were visible as distinct bands on a blue background.

Immunofluorescence staining. The nuclear/cytoplasmic distribution of $\beta$-catenin was detected by immunofluorescence staining. Briefly, the cells were seeded on sterile glass slides located in the 6-well plates. Then, the cells were fixed using $4 \%$ paraformaldehyde solution, permeabilized by $0.1 \%$ TritonX-100, and blocked 15 min with goat serum. Primary antibody against $\beta$-catenin was applied overnight at $4^{\circ} \mathrm{C}$. The bound of $\beta$-catenin antibody was visualized using Cy3-fluorescently labeled antibody, and the nuclei were counterstained with DAPI (4,6-diamidino-2-phenylindole). The distribution of $\beta$-catenin was detected using BX53 microscopy (OLYMPUS, Tokyo, Japan).

Luciferase assay. OC cells seeded in 24-well plates were co-transfected with M50 Super $8 \times$ TOPFlash (Addgene, Cambridge, MA, USA) and pRL-null Renilla luciferase to detect $\beta$-catenin transcriptional activity. Twenty-four hours later, dual-luciferase reporter assay system (Promega, Madison, WI, USA) was utilized to measure the firefly and renilla luciferase activity according to the manufacturer's instructions. The activity of firefly was normalized to Renilla.

Statistical analysis. Statistical analyses were carried out using the Prism5 (GraphPad) software. Data between independent groups were compared by Student's t-tests. Quantitative results were presented as mean \pm SD (standard deviation). Statistical significance was shown as: ${ }^{*}, \mathrm{p}<0.05$; ${ }^{* *}$, $\mathrm{p}<0.01$ and $^{* * *}, \mathrm{p}<0.001$.

\section{Results}

Knockdown of TRIM28 in OC cells. In order to explore whether TRIM28 is involved in OC cells metastasis in vitro, TRIM28-silenced A2780 and OVCAR-3 cells were established. The knockdown efficiency of TRIM28 shRNA was analyzed with western blotting and real-time PCR. As shown in Figure $1 \mathrm{~A}$ and B, the expression level of TRIM28 in A2780 and OVCAR-3 cells was markedly decreased after TRIM28 silencing as compared to that of the control cells.

Knockdown of TRIM28 inhibited the migratory and invasive capability of OC cells. Next, we investigated the effects of TRIM28 knockdown in OC cells. We found that the migration and invasion in TRIM28-silenced A2780 and OVCAR-3 cells were significantly decreased (Figure 2A and B). We further detected the expression levels of MMP-2 and MMP-9 through western blotting after knockdown of
A

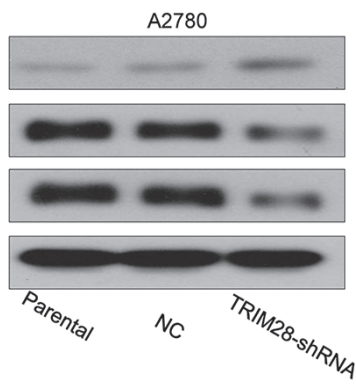

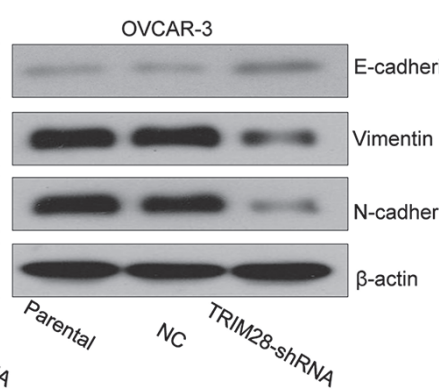

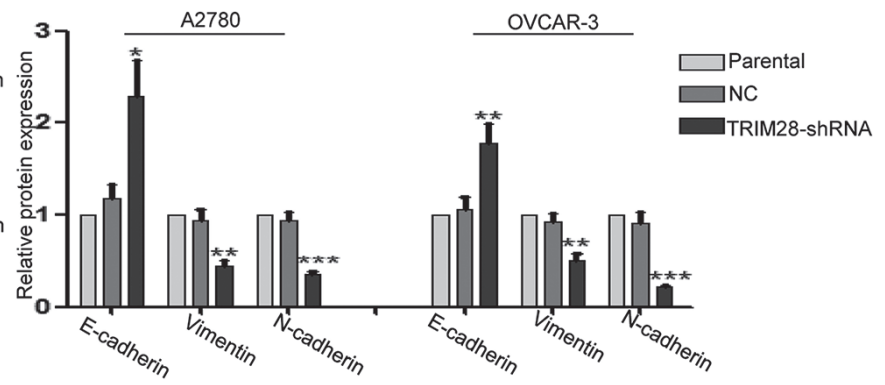

B

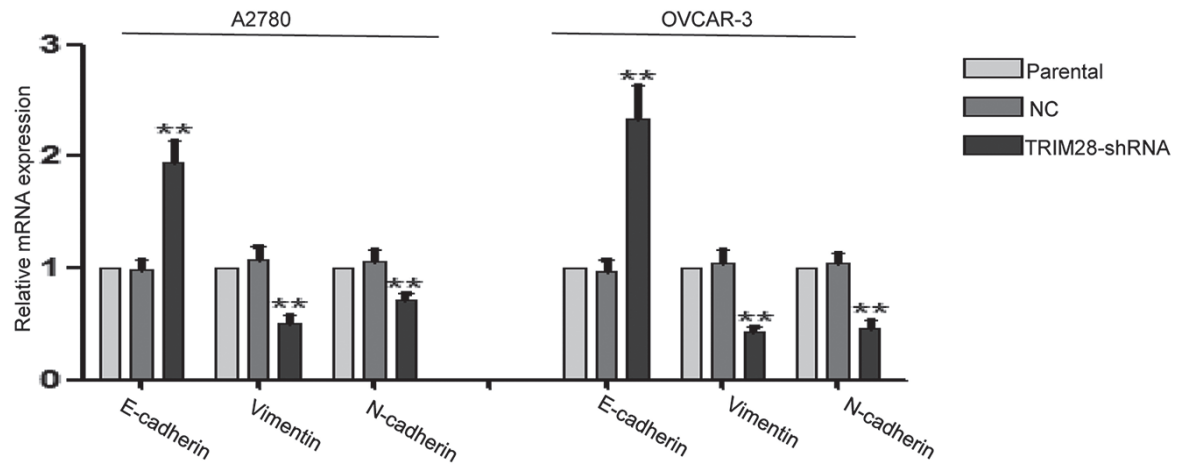

Figure 3. TRIM28 silencing inhibited the process of EMT in OC cells. (A) The protein levels of E-cadherin, Vimentin and N-cadherin were detected by western blotting in TRIM28-silenced TRIM28-silenced A2780 and OVCAR-3 cells. (B) Real-time PCR was performed to measure the mRNA expression of E-cadherin, Vimentin and N-cadherin after TRIM28 silencing in A2780 and OVCAR-3 cells. Date were presented as mean \pm SD. ${ }^{* *} p<0.01$ and ${ }^{* * *} \mathbf{p}<0.001$ versus the $\mathrm{NC}$ group. 
TRIM28. As shown in Figure 2C, TRIM28 silencing remarkably inhibited the expression of MMP-2 and MMP-9 in both A2780 and OVCAR-3 cells. The activities of MMP-2 and MMP-9 were also decreased in TRIM28-silenced A2780 and OVCAR-3 cells (Figure 2D). Collectively, the knockdown of TRIM28 inhibits the mobility of OC cells, which is accompanied by downregulated MMP-2 and MMP-9.

Knockdown of TRIM28 suppressed EMT process of OC cells. Furthermore, we investigated whether TRIM28 are involved in the EMT process of OC cells. E-cadherin, $\mathrm{N}$-cadherin and Vimentin are the important markers of EMT [20]. Results from the western blot analysis illustrated that the expression of E-cadherin in TRIM28-silenced A2780 and OVCAR-3 cells was significantly upregulated, while that of $\mathrm{N}$-cadherin and Vimentin were markedly downregulated (Figure 3A). Similar results were also observed at mRNA level (Figure 3B). Taken together, our data show that knockdown of TRIM28 impairs the EMT process of OC cells in vitro.
Knockdown of TRIM28 inhibits the activation of Wnt $/ \beta$ catenin pathway. Wnt/ $\beta$-catenin pathway is an important pathway which can facilitate transcriptional alterations and then drive EMT process [21]. Thus, we first detected the distribution of $\beta$-catenin in OC cells by performing immunofluorescent staining and western blot analysis. We noted that TRIM28 inhibition promoted the nuclear export of $\beta$-catenin in A2780 and OVCAR-3 cells (Figure 4A and B). The activity of $\beta$-catenin of these cells was suppressed by TRIM 28 shRNA (Figure 4C). Additionally, knockdown of TRIM28 led to an increase in phosphorylated $\beta$-catenin (Ser33/37) and a decrease in total $\beta$-catenin (Figure $4 \mathrm{D}$ ). The expression levels of $\beta$-catenin downstream target genes AXIN2, TCF1 and LEF1 were also significantly downregulated after silencing of TRIM28 (Figure 4F).

Further, the $\beta$-catenin-S33Y plasmid was used to upregulate the expression of active $\beta$-catenin in OC cells. Here, we found that the forced overexpression of active $\beta$-catenin partly

A
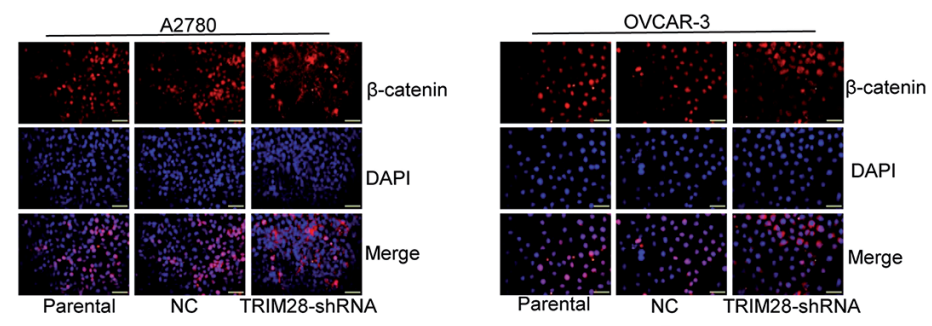

B

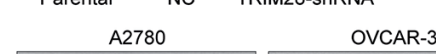

OVCAR-3

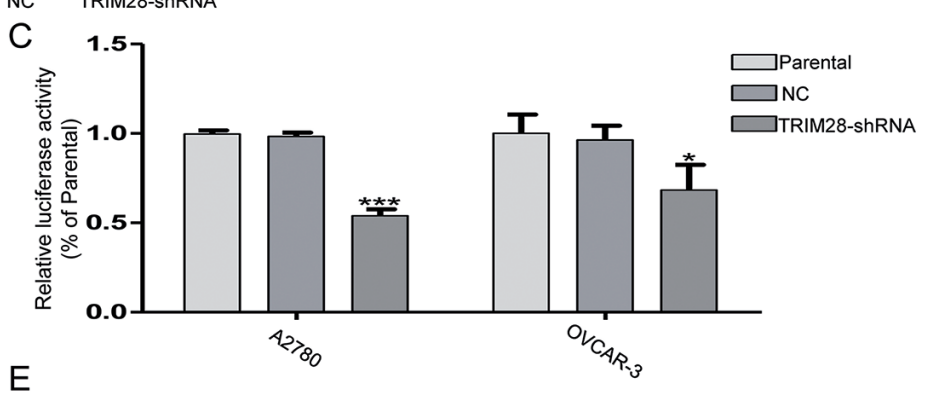

D
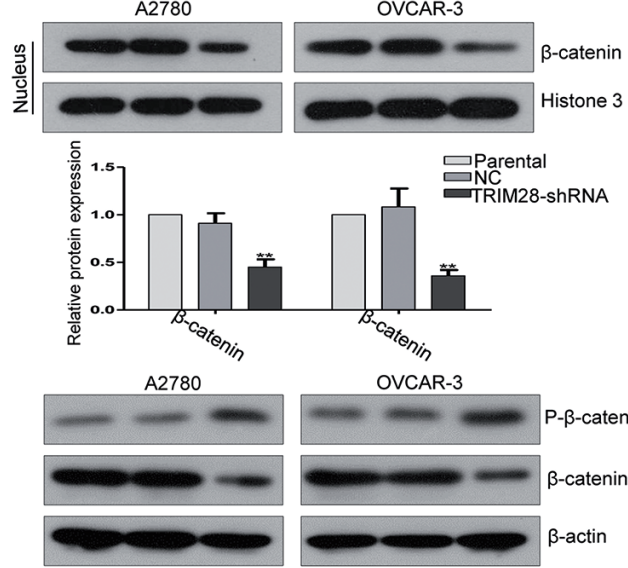

OVCAR-3

E
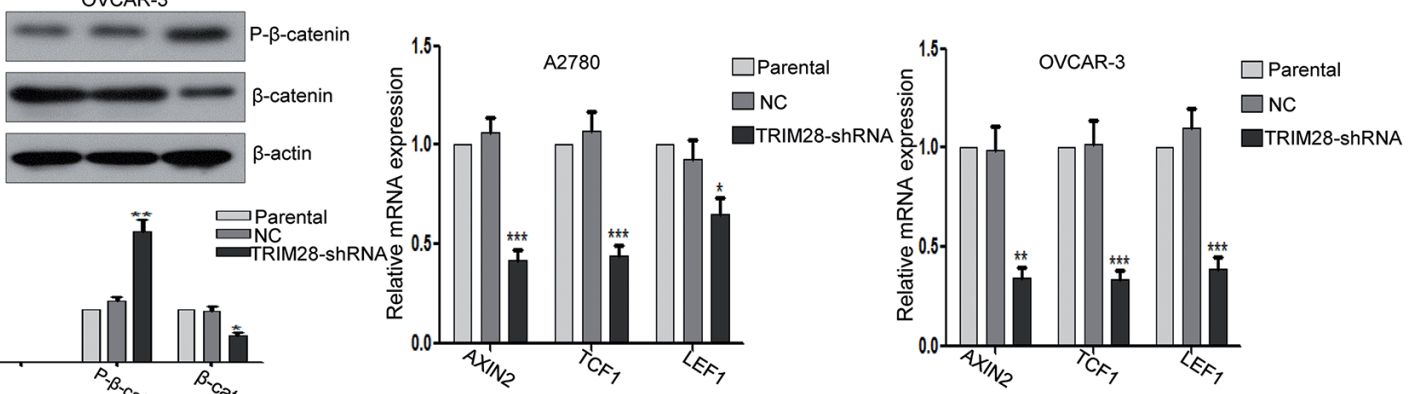

Figure 4. Knockdown of TRIM28 suppressed the activation of Wnt/ $\beta$-catenin signaling pathway. (A) The distribution of $\beta$-catenin in nucleus/cytoplasm was detected by immunofluorescence staining after knockdown of TRIM28 in A2780 and OVCAR-3 cells. (B) Nuclear expression of $\beta$-catenin in A2780 and OVCAR-3 cells with or without $\beta$-catenin silencing was measured by western blotting. (C) The activity of $\beta$-catenin in A2780 and OVCAR-3 cells was evaluated after knockdown of TRIM28 by luciferase assay. (D)The protein levels of phosphorylated $\beta$-catenin (Ser33/37) and total $\beta$-catenin in TRIM28-silenced A2780 and OVCAR-3 cells were assessed by western blotting. (E) The mRNA expression levels of AXIN2, TCF1 and LEF1 in A2780 and OVCAR-3 cells were analyzed after TRIM28 silencing by real-time PCR. Date were presented as mean $\pm \mathrm{SD} .{ }^{*} \mathrm{p}<0.05,{ }^{* *} \mathrm{p}<0.01$ and ${ }^{\star * *} \mathrm{p}<0.001$ versus the NC group. 
abolished TRIM28 shRNA-induced expression alteration of EMT-related proteins (Figure 5A). Moreover, TRIM28silenced cells reacquired strong migration and invasion ability when transfected with $\beta$-catenin-S33Y plasmid (Figure 5B and C). Taken together, these data suggest that TRIM28 is involved in the EMT process of OC cells at least by orchestrating Wnt $/ \beta$ catenin signaling pathway.

\section{Discussion}

TRIM28 is a critical component in several multiple-protein complexes and is involved in lots of biological processes [22]. TRIM28 is reportedly participated in the activation of EMT process in many cancers [17-19]. However, whether and how TRIM28 can regulate EMT process of OC cells are uncharted.

RNA interference (RNAi) is considered as an outstanding science discovery in the 21st century [23], which is a process of homologous mRNA inducing double-stranded RNA degradation and blocking the corresponding gene expression, thus resulting in specific post-transcriptional gene silencing [24]. In order to explore whether TRIM28 is involved in the metastasis of OC cells, two OC cell lines with stable low expression of TRIM28 were established in this study. Interestingly, we found that the migratory and invasive ability of OC cells was significantly suppressed after knocking down TRIM28. It is reported that epithelial cells differentiate into mesenchymal cells by undergoing an EMT transformation [15]. MMP-2 and MMP-9 are two essential gelatinases of matrix metalloproteinase family [25], which are considered to contribute to cancer cell metastasis by degrading extracellular matrix components [26]. We also found that the expression levels and activities of MMP-2 and MMP-9 were also downregulated in the TRIM28silenced cells. Our findings here suggest that the malignant OC cells require TRIM28 expression to maintaining their high metastatic phenotype.

Cell adhesion is essential for maintaining the functions and features of different cells, in which the cadherin family proteins, such as E-cadherin, $\mathrm{N}$-cadherin and P-cadherin, play critical regulatory role. The loss of E-cadherin (an epithelial marker) and the elevation of $\mathrm{N}$-cadherin and P-cadherin (mesenchymal markers) are hall marks of EMT initiation [27]. The intermediate filament protein Vimentin is also a widely

A
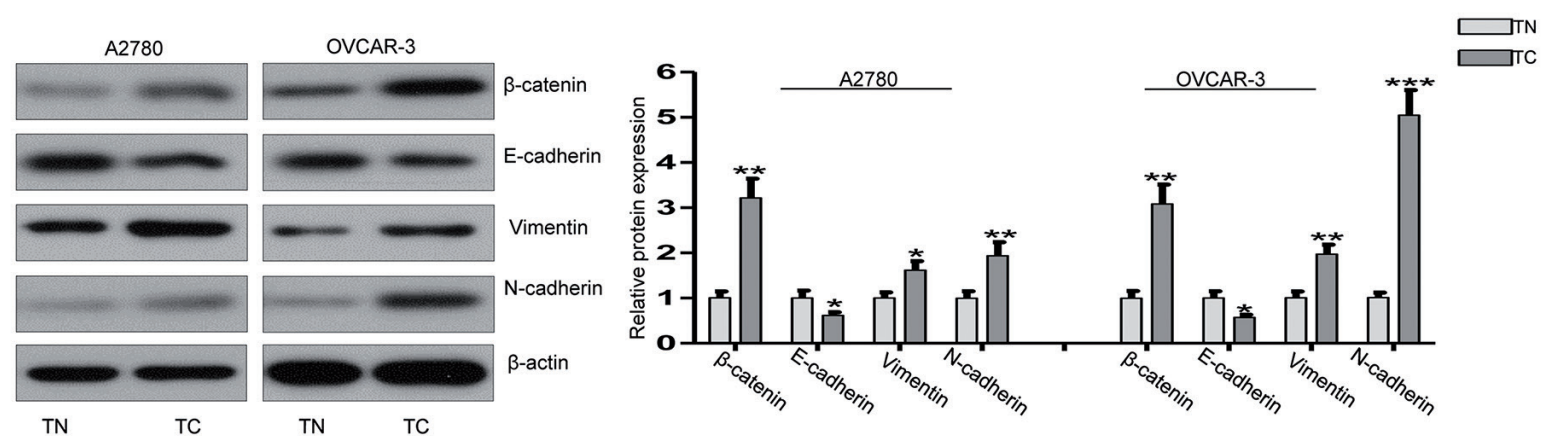

B

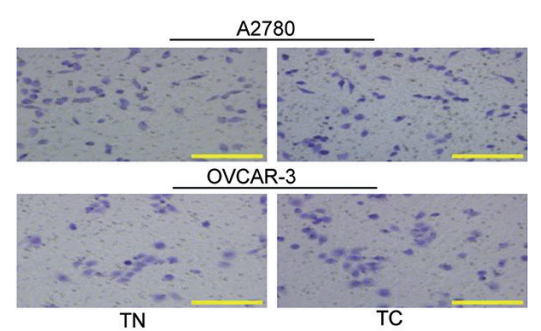

c
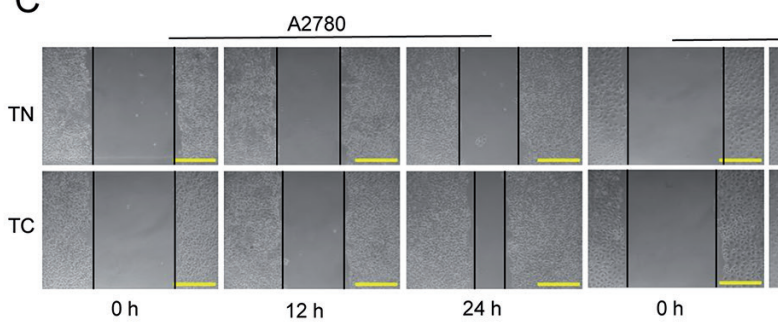

OVCAR-3
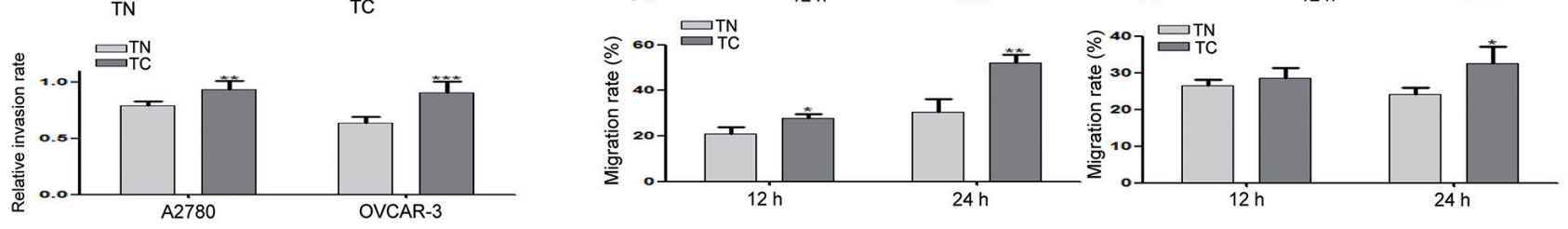

Figure 5. Overexpression of $\beta$-catenin alleviated TRIM28-silencing-mediated inhibition of EMT. (A) The expression levels of $\beta$-catenin, E-cadherin, Vimentin and N-cadherin in A2780 and OVCAR-3 cells were evaluated by western blotting after overexpression of $\beta$-catenin by transfection of $\beta$-cateninS33Y plasmid. (B) The ability of invasion of A2780 and OVCAR-3 cells was detected by transwell assay after overexpression of $\beta$-catenin by transfecting $\beta$-catenin-S33Y plasmid. (C) The ability of migration in TRIM28-silenced A2780 and OVCAR-3 cells with transfection of $\beta$-catenin-S33Y plasmid was examined by wound healing assay. TN: TRIM28-shRNA+NC; TC: TRIM28-shRNA+ $\beta$-catenin-S33Y. Date were presented as mean \pm SD. ${ }^{\star}$ p $<0.05$, ${ }^{\star *} \mathbf{p}<0.01$ and ${ }^{\star * *} \mathbf{p}<0.001$ versus the TN group. 
recognized marker of in the EMT process[28]. In the present study, we found that the TRIM28 shRNA-transfected OC cells underwent EMT by analyzing the expression of the above mentioned EMT-related proteins.

EMT process can be initiated upon the activation of various signaling pathways, including transforming growth factor $\beta$ (TGF- $\beta$ ), Notch, Hedgehog, and Wnt/ $\beta$-catenin, etc [29]. It is worth noting that the $\mathrm{Wnt} / \beta$-catenin signaling pathway is involved in the EMT process in a variety of cancers, such as breast cancer [21], gastric cancer [30], colorectal cancer [31], pancreatic cancer [32] and OC [33]. $\beta$-catenin is the central component of Wnt/ $\beta$-catenin signaling pathway $[34,35]$, whose function is dependent on its cellular localization. Nuclear accumulation of $\beta$-catenin can activate oncogenic targets and promote tumor initiation and progression [36]. The phosphorylation of $\beta$-catenin at Ser33, Ser37 and Thr41 mediated by glycogen synthase kinase 3 beta (GSK3 $\beta$ ) facilitates the ubiquitylation of $\beta$-catenin, eventually leading its degradation [37]. When being activated, $\beta$-catenin can translocate into cell nuclei and promote the expression of its downstream targets such as AXIN2, TCF1 and LEF1 [38]. Our current work revealed that the nuclear export of $\beta$-catenin was increased, its activity was attenuated and its phosphorylation was enhanced in TRIM28-silenced OC cells. These results suggest that TRIM28 is required for the activation of $\beta$-catenin. Further, the forced overexpression of active $\beta$-catenin rendered TRIM28-silenced cells with strong migration and invasion capability. Taken together, our study reveals that TRIM28 mediates the EMT process of OC cells at least by regulating of $\mathrm{Wnt} / \beta$-catenin signaling pathway.

In summary, we demonstrate that the silencing of TRIM28 inhibits EMT process of OC cells via blocking Wnt/ $\beta$-catenin signaling pathway. Our findings suggest TRIM 28 as a potential therapeutic target of OC.

Acknowledgements: This study was supported by a grant from the Doctoral Startup Foundation of Liaoning Province (No. 20141044).

\section{References}

[1] TORRE LA, BRAY F, SIEGEL RL, FERLAY J, LORTETTIEULENT J et al. Global cancer statistics, 2012. CA Cancer J Clin 2015; 65: 87-108. https://doi.org/10.3322/caac.21262

[2] SON DS, KABIR SM, DONG YL, LEE E, ADUNYAH SE. Inhibitory effect of tumor suppressor $\mathrm{p} 53$ on proinflammatory chemokine expression in ovarian cancer cells by reducing proteasomal degradation of IkappaB. PLoS One 2012; 7: e51116. https://doi.org/10.1371/journal.pone.0051116

[3] DOGAN NU, SCHNEIDER A, CHIANTERA V, DOGAN S, DURSUN P. Tertiary cytoreduction in the setting of recurrent ovarian cancer (Review). Oncol Lett 2013; 6: 642-647. https:// doi.org/10.3892/ol.2013.1445

[4] JIN JH, KIM HJ, KIM CY, KIM YH, JU W et al. Association of plasma adiponectin and leptin levels with the development and progression of ovarian cancer. Obstet Gynecol Sci 2016;59:279-285. https://doi.org/10.5468/ ogs.2016.59.4.279

[5] BUNCH H, CALDERWOOD SK. TRIM28 as a novel transcriptional elongation factor. BMC Mol Biol 2015; 16: 14. https://doi.org/10.1186/s12867-015-0040-X

[6] SANTOS J, GIL J. TRIM28/KAP1 regulates senescence. Immunol Lett 2014; 162: 281-289. https://doi.org/10.1016/j. imlet.2014.08.011

[7] SINGH K, CASSANO M, PLANET E, SEBASTIAN S, JANG SM et al. A KAP1 phosphorylation switch controls MyoD function during skeletal muscle differentiation. Genes Dev 2015; 29: 513-525. https://doi.org/10.1101/gad.254532.114

[8] MILES DC, ALEXANDRA DE VRIES N, GISLER S, LIEFTINK C, AKHTAR W et al. TRIM28 is an Epigenetic Barrier to Induced Pluripotent Stem Cell Reprogramming. Stem Cells 2016; 35: 147-157. https://doi.org/10.1002/stem.2453

[9] ZHOU XF, YU J, CHANG M, ZHANG M, ZHOU D et al. TRIM28 mediates chromatin modifications at the TCRalpha enhancer and regulates the development of T and natural killer T cells. Proc Natl Acad Sci U S A 2012; 109: 20083-20088. https://doi.org/10.1073/pnas.1214704109

[10] ADDISON JB, KOONTZ C, FUGETT JH, CREIGHTON CJ, CHEN D et al. KAP1 promotes proliferation and metastatic progression of breast cancer cells. Cancer Res 2015; 75: 344-355. https://doi.org/10.1158/0008-5472.CAN-14-1561

[11] YU C, ZHAN L, JIANG J, PAN Y, ZHANG H et al. KAP-1 is overexpressed and correlates with increased metastatic ability and tumorigenicity in pancreatic cancer. Med Oncol 2014;31: 25. https://doi.org/10.1007/s12032-014-0025-5

[12] QI ZX, CAI JJ, CHEN LC, YUE Q, GONG Y et al. TRIM28 as an independent prognostic marker plays critical roles in glioma progression. J Neurooncol 2016; 126: 19-26. https:// doi.org/10.1007/s11060-015-1897-8

[13] LIU L, ZHAO E, LI C, HUANG L, XIAO L et al. TRIM28, a new molecular marker predicting metastasis and survival in early-stage non-small cell lung cancer. Cancer Epidemiol 2013; 37: 71-78. https://doi.org/10.1016/j.canep.2012.08.005

[14] CUI Y, YANG S, FU X, FENG J, XU S et al. High levels of KAP1 expression are associated with aggressive clinical features in ovarian cancer. Int J Mol Sci 2014; 16: 363-377. https://doi. org/10.3390/ijms16010363

[15] TSAI JH, YANG J. Epithelial-mesenchymal plasticity in carcinoma metastasis. Genes Dev 2013; 27: 2192-2206. https:// doi.org/10.1101/gad.225334.113

[16] OMBRATO L, MALANCHI I. The EMT universe: space between cancer cell dissemination and metastasis initiation. Crit Rev Oncog 2014; 19: 349-361. https://doi.org/10.1615/ CritRevOncog.2014011802

[17] VENKOV CD, LINK AJ, JENNINGS JL, PLIETH D, INOUE $\mathrm{T}$ et al. A proximal activator of transcription in epithelialmesenchymal transition. J Clin Invest 2007; 117: 482-491. https://doi.org/10.1172/JCI29544

[18] CHEN L, MUNOZ-ANTONIA T, CRESS WD. Trim28 contributes to EMT via regulation of E-cadherin and $\mathrm{N}$-cadherin in lung cancer cell lines. PLoS One 2014; 9: e101040. https:// doi.org/10.1371/journal.pone. 0101040 
[19] LIN LF, LI CF, WANG WJ, YANG WM, WANG DD et al. Loss of ZBRK1 contributes to the increase of KAP1 and promotes KAP1-mediated metastasis and invasion in cervical cancer. PLoS One 2013; 8: e73033. https://doi.org/10.1371/journal. pone.0073033

[20] XU Q, DENG F, QIN Y, ZHAO Z, WU Z et al. Long noncoding RNA regulation of epithelial-mesenchymal transition in cancer metastasis. Cell Death Dis 2016; 7: e2254. https:// doi.org/10.1038/cddis.2016.149

[21] XIAO C, WU CH, HU HZ. LncRNA UCA1 promotes epithelial-mesenchymal transition (EMT) of breast cancer cells via enhancing Wnt/beta-catenin signaling pathway. Eur Rev Med Pharmacol Sci 2016; 20: 2819-2824.

[22] WEI C, CHENG J, ZHOU B, ZHU L, KHAN MA et al. Tripartite motif containing 28 (TRIM28) promotes breast cancer metastasis by stabilizing TWIST1 protein. Sci Rep 2016; 6: 29822. https://doi.org/10.1038/srep29822

[23] SU Z, LIU G, FANG T, WANG Y, ZHANG H et al. Silencing MRP1-4 genes by RNA interference enhances sensitivity of human hepatoma cells to chemotherapy. Am J Transl Res 2016; 8: 2790-2802.

[24] SIOUD M. RNA interference: mechanisms, technical challenges, and therapeutic opportunities. Methods Mol Biol 2015; 1218: 1-15. https://doi.org/10.1007/978-1-4939-1538-5 1

[25] LEVICAR N, NUTTALL RK, LAH TT. Proteases in brain tumour progression. Acta Neurochir (Wien) 2003; 145: 825-838. https://doi.org/10.1007/s00701-003-0097-z

[26] JACOB A, PREKERIS R. The regulation of MMP targeting to invadopodia during cancer metastasis. Front Cell Dev Biol 2015; 3: 4. https://doi.org/10.3389/fcell.2015.00004

[27] GHELDOF A, BERX G. Cadherins and epithelial-to-mesenchymal transition. Prog Mol Biol Transl Sci 2013; 116:317-336. https://doi.org/10.1016/B978-0-12-394311-8.00014-5

[28] SATELLI A, LI S. Vimentin in cancer and its potential as a molecular target for cancer therapy. Cell Mol Life Sci 2011; 68: 3033-3046. https://doi.org/10.1007/s00018-011-0735-1

[29] LIU X, YUN F, SHI L, LI ZH, LUO NR et al. Roles of Signaling Pathways in the Epithelial-Mesenchymal Transition in Cancer. Asian Pac J Cancer Prev 2015; 16: 6201-6206. https://doi. org/10.7314/APJCP.2015.16.15.6201
[30] LIU X, LI Z, SONG Y, WANG R, HAN L et al. AURKA induces EMT by regulating histone modification through Wnt/betacatenin and PI3K/Akt signaling pathway in gastric cancer. Oncotarget 2016; 7: 33152-33164. https://doi.org/10.18632/ oncotarget.8888

[31] HU TH, YAO Y, YU S, HAN LL, WANG WJ et al. SDF-1/ CXCR4 promotes epithelial-mesenchymal transition and progression of colorectal cancer by activation of the Wnt/betacatenin signaling pathway. Cancer Lett 2014; 354: 417-426. https://doi.org/10.1016/j.canlet.2014.08.012

[32] XU W, WANG Z, ZHANG W, QIAN K, LI H et al. Mutated Kras activates $\mathrm{CDK} 8$ to stimulate the epithelial-to-mesenchymal transition in pancreatic cancer in part via the Wnt/betacatenin signaling pathway. Cancer Lett 2015; 356: 613-627. https://doi.org/10.1016/j.canlet.2014.10.008

[33] YOSHIOKA S, KING ML, RAN S, OKUDA H, MACLEAN JA $2 \mathrm{ND}$ et al. WNT7A regulates tumor growth and progression in ovarian cancer through the WNT/beta-catenin pathway. Mol Cancer Res 2012; 10: 469-482. https://doi.org/10.1158/15417786.MCR-11-0177

[34] MAO Y, XU J, LI Z, ZHANG N, YIN H et al. The role of nuclear beta-catenin accumulation in the Twist2-induced ovarian cancer EMT. PLoS One 2013; 8: e78200. https://doi. org/10.1371/journal.pone.0078200

[35] JAMIESON C, SHARMA M, HENDERSON BR. Wnt signaling from membrane to nucleus: beta-catenin caught in a loop. Int J Biochem Cell Biol 2012; 44: 847-850. https://doi. org/10.1016/j.biocel.2012.03.001

[36] MACDONALD BT, TAMAI K, HE X. Wnt/beta-catenin signaling: components, mechanisms, and diseases. Dev Cell 2009; 17: 9-26. https://doi.org/10.1016/j.devcel.2009.06.016

[37] VERHEYEN EM, GOTTARDI CJ. Regulation of Wnt/betacatenin signaling by protein kinases. Dev Dyn 2010; 239: 34-44. https://doi.org/10.1002/dvdy.22019

[38] LI XF, XU H, ZHAO YJ, TANG DZ, XU GH et al. Icariin Augments Bone Formation and Reverses the Phenotypes of Osteoprotegerin-Deficient Mice through the Activation of Wnt/ beta -Catenin-BMP Signaling. Evid Based Complement Alternat Med 2013; 2013: 652317. https://doi. org/10.1155/2013/652317 